\title{
'If I had a hedge fund, I would cure diabetes': endogenous mechanisms for creating public goods
}

\author{
John Liechty ${ }^{1}$ (1) Stefan Wuyts ${ }^{1}[$
}

Received: 8 March 2021 / Accepted: 26 July 2021 / Published online: 6 September 2021

(c) The Author(s), under exclusive licence to Springer Nature Switzerland AG 2021

\begin{abstract}
We consider the problem of organizing capital to produce public goods with broad societal value. We review why market corrections via government subsidies or philanthropic initiatives are inadequate, in addition to considering the paradox of patents. Our proposed mechanism (an Ever-growing Prize and a Patent Repository) directs capital towards two innovation problems routinely overlooked: (1) problems for which the reward is insufficient even with established mechanisms (e.g. patents or academic prestige), and (2) problems for which the reward is large, but the effort risk is incalculable. The proposed hedge fund mechanism facilitates crowdsourcing, addressing the challenge of determining problems with broad societal interest; the ever-growing prize allows for an emergent rather than predetermined reward; the patent repository turns private intellectual property into a public good for target problems while circumventing the inventors' threat of patent expiration. We guide this discussion by considering two problems: treating Cystic Fibrosis and curing Diabetes.
\end{abstract}

Keywords Capital $\cdot$ Public goods $\cdot$ Patents $\cdot$ Innovation $\cdot$ Hedge fund

JEL Classification L31 $\cdot \mathrm{O} 31 \cdot \mathrm{O} 34 \cdot \mathrm{O} 36$

\section{Introduction}

In the musical Fiddler on the Roof, see Bock (1964), the main character Tevye (a peasant living in Imperial Russia) wonders what life would be like (and how he might influence it) as he sings "If I were a rich man." In this paper, we explore a similar theme, with an emphasis on using private wealth to improve the welfare of the general public - especially for problems where capitalism, government action

John Liechty

jc112@psu.edu

1 Department of Marketing, Smeal College of Business, Pennsylvania State University, Business Building, University Park, PA 16802, USA 
and philanthropy have yet to succeed. We postulate that a modern equivalent of "If I were a rich man," is "If I had a hedge fund." As a point of illustration of how competitive market forces can be organized in a way that better aligns with the interest of the general public, we describe how the owner of a hedge fund could use this aggregation of capital to cure diabetes.

We start by reviewing the inherent challenges facing a society as it creates legal structures to facilitate optimal levels of innovation. We then review existing mechanisms for solving important, society-wide problems: competitive markets, contests, and subsidies. While successful in addressing certain problems, structural constraints of these mechanisms lead to a type of market failures, ${ }^{2}$ implicit in Marx's critique of capitalism ${ }^{3}$ (which we frame as: the holders of excess capital are either unwilling or incapable of putting excess labor, stored as capital, to work solving problems that are of interest to a substantial portion of those who helped create the excess labor, meaning the public).

The first part of our proposed solution—an Ever-Growing Prize—provides a mechanism where an emergent price is set by society such that a sufficient amount of capital from the competitive markets will be allocated to finding a solution to a target problem (e.g. curing diabetes). The second part—a Patent Repository—provides a legal structure where the barriers for sharing Intellectual Property (for the express purpose of solving a target problem) are eliminated, while leaving traditional protections in place for other problems; it also provides a clear path for rewarding contributors if their ideas are used to solve the target problem.

\footnotetext{
${ }^{1}$ We readily concede that other transformative enterprises, which rapidly aggregate vast amounts of wealth in the hands of a select few entrepreneurs-who early in their careers might have chosen to sing, "If I had a Tech. Firm," offer viable alternatives to obtaining the economic power needed to create the mechanism described in this paper.

${ }^{2}$ Economics has focused considerable attention on identifying and proposing solutions to market failures-see Bator (1958) and Medema (2007), where the market mechanism fails to achieve an efficient equilibrium. Less attention has been focused on how the structural limits of markets and the proposed solutions (government and philanthropy) leave important problems unaddressed, which could be viewed as a failure of the market system, see Bateman (2015). Efforts to overcome market failures have exposed the inherent challenge in executing non market-based solutions and added government failures (where a government's intervention to solve a market failure causes even greater inefficiencies) and philanthropic failures (where the preferences of philanthropists and challenges of oversight and information asymmetry fail to bring sufficient capital to address problems of broad interest) to the list of credible criticisms of the limits of alternative efforts to organize capital in a manner that seeks to effectively solve problems of broad public interest. In general, the problem of the market failing to provide a sufficient amount of innovation in society is well established in Economics, see Williams (2012).

${ }^{3}$ The call for the abolishment of private property in The Communist Manifesto, see Marx and Engels (1848), suggests hostility to the idea that the few individuals who amass great wealth, via the markets, have an inherent ability to decide which problems the general public would like to have solved.
} 


\section{The Innovator's dilemma}

Three forms of risk are inherent to innovation ${ }^{4}$ : (1) effort risk-the amount of effort needed to solve a problem is unknown a priori; (2) reward risk - the amount society will pay for a solution is unknown a priori; (3) free-rider risk-the amount of (created) value captured by the innovator is small to nonexistent once a solution is in the public domain. In light of these risks, one of the primary tasks of economics is to invent mechanisms that allow a society to organize capital to create public goods ${ }^{5}$ such as knowledge, and a primary task of political systems is to implement these mechanisms (Anomaly 2015).

How can a society motivate groups of individuals to spend sustained efforts to solve important problems? How does a society determine which problems are important? The profit motive from competitive markets, provides a well-tested mechanism for prioritizing problems and rewarding inventors. The corporation is a legal structure that allows capital to be organized for problems that meet two criteria: ${ }^{6}(1)$ the expected profit is above a threshold (defining the expected profit threshold, see Fig. 1); and (2) the risk of going bankrupt before bringing a product to market is negligible (defining the innovation boundary, again see Fig. 1).

As illustrated in Fig. 1, the expected profit and risk criteria lead to two types of market failures, i.e. areas of innovation where problems important to large parts of the public remain unaddressed. A first type of market failure occurs when the expected profit falls below a threshold, making the problem unattractive in competitive markets despite the low associated risk. ${ }^{7}$ A second type of market failure arises when the effort risk is exorbitant, making the problem unattractive to firms despite high expected profits (e.g. finding a cure for diabetes). Attempts to redress market failures, using capital captured through taxation or set aside by philanthropists, can be broadly categorized as Pull mechanisms (e.g. contests) or Push mechanisms (e.g. subsidies)—see Reich (2000), Glennerster et al. (2006) and Mueller-Langer (2013), both of which have limitations.

\footnotetext{
${ }^{4}$ Our focus differs from related management literature in that we are interested in organizing capital across society, which could engage a wide variety of firms and institutions, as opposed to studying the long-term survival of a single company in the face of technological change, see Christensen (1997).

5 A public good is non-excludable (an individual cannot be kept from using it) and non-rivalrous (use by one individual does not restrict use by another individual); a lighthouse (Samuelson 1970, footnote on page 44), is a classic example of a public good.

${ }^{6}$ It is worth noting that as private wealth increases, markets will expand both "downward", by providing solutions which are less profitable, and "outward", by addressing problems with greater bankruptcy risk.

${ }^{7}$ Such as the production and distribution of a pneumococcal vaccine for countries in the developing world.
} 


\section{Pull mechanisms and the ever-growing prize}

Pull mechanisms require innovators to ${ }^{8}$ bear the effort risk and innovators are only compensated once a solution has been developed. A first, traditional pull mechanism is a patent regime, ${ }^{9}$ where the prize is the inventor's ability to charge a monopoly price until the patent expiration date. The source of reward risk associated with patents is primarily competition (alternative market solutions, not dependent on the patent, may arise) and, to a lesser degree, political (a patent regime can be changed through legislation or patents become void through a lack of enforcement by governments). A second pull mechanism, developed to address problems that fall below the expected profit threshold, is the advanced market commitment. Using this mechanism removes competitive and political sources of reward risk by having a credible legal entity (e.g. the World Health Organization) guarantee a market ${ }^{10}$ (see Berndt et al. 2007; Cernuschi et al. 2011; GAVI 2017). A third mechanism, resurgent in popularity, intended to overcome constraints associated with competitive markets and government intervention, is a contest with a cash prize, such as the Ansari XPRIZE ${ }^{11}$ in which the reward risk is essentially reduced to whether the sponsor can be compelled to pay.

The first part of our proposal is an alternative prize mechanism. Prizes ${ }^{12}$ have a long, but erratic history as a mechanism for fostering innovation and broadening the pool ${ }^{13}$

\footnotetext{
8 The Prize grows in three ways: (1) by ongoing donations to the Cure Fund, (2) by investment profits from managing the Cure Fund; and (3) by donated management fees that come for managing the Companion Fund-see Fig. 2. Although there are a range of investment strategies available, the Cure Fund would primarily follow "wealth-preserving" strategies reducing the risk of significant losses. The evergrowing nature of the prize entails that the appreciation of the capital would be allowed to continue until a cure was found.

${ }^{9}$ Patents are a government solution for overcoming the time-inconsistency market failure-see Berndt et al. (2007), which results in the inherent free-rider problem for public goods (typically goods with a high fixed cost to invent, a low marginal cost to produce, and critically-in the absence of a patent-no ability to exclude people from using the good), where consumers are willing to pay the marginal cost of the good once created. A patent overcomes this problem by granting a monopoly, allowing the holder to overcharge (above the marginal cost) and make a profit sufficient to compensate for their upfront investment. Patents, however, while in force, create two additional market failures: first is the dead weight loss, where individuals who cannot afford to pay the monopoly price are excluded from the market; second is the removal of the patented idea from the public domain, creating an artificial anticommon, see Hardin (1968), Heller and Eisenberg (1998), for knowledge, which imposes higher costs on development of new knowledge. Interestingly, recent work, see Boldrin and Levine (2013), related to patents shows that "there is no empirical evidence that they serve to increase innovation and productivity, unless productivity is identified with the number of patents awarded—which as evidence shows, has no correlation with measured productivity.".

10 This mechanism has helped patented pneumococcal vaccines (where patents by themselves had failed) become available in the developing world, by guaranteeing the purchase of quantities at a fixed price sufficient to induce the patent holders to invest in requisite marginal production capacity.

${ }^{11}$ A $\$ 10$ million prize for the first non-government organization to successfully launch a reusable manned spacecraft into space two times, within a 2-week period, see Schwartz (2004).

${ }^{12}$ For a catalog of innovation prize efforts, see KEI (2008) and McKinsey \& Company (2019).

${ }^{13}$ Crowdsourcing (used in this context to indicate bringing together human capital—such as data science expertise - to solve a problem, as opposed to bringing together financial capital to fund a prize) has
} 


\section{Competitive Markets}

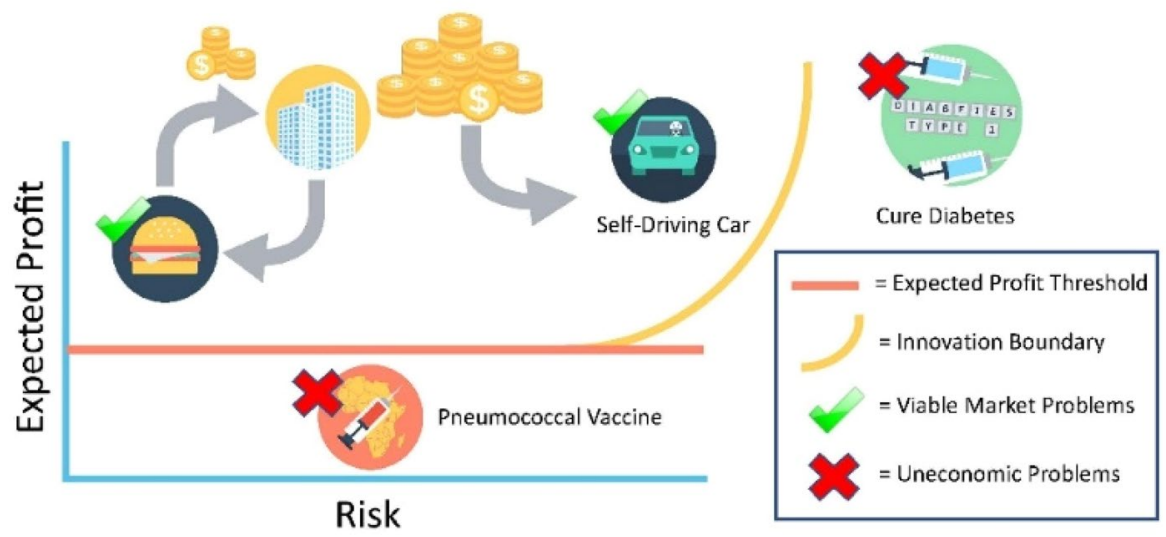

Fig. 1 Competitive markets solve problems where profit, adjusted for risk, is above a threshold (marked by the expected profit threshold) and risk of going bankrupt is negligible (marked by the innovation boundary). It is worth noting that the risk-adjusted boundary can vary by firm, as the introduction of a new solution can cannibalize, see Chandy and Tellis (1998) and Tellis (20135), an existing solution already offered by the firm

of human capital ${ }^{14}$ (Brunt et al. 2012; Clancy and Moschini 2013; Gewin 2017; Levine 2009; Murray et al. 2012; Sobel 1996; Williams 2012). A longstanding challenge with using prizes is determining the size of the prize ${ }^{15}$ (Berndt and Hurvitz 2005; Berndt et al. 2007; Grabowski 2008; Kalil 2006; Kremer and Williams 2010; Levine 2009). The optimal size can, in theory, be derived in a game-theoretic sense by finding a Nash equilibrium $^{16}$ - if and only if we have accurate estimates of preferences for every economically

\footnotetext{
${ }^{14}$ In a broader framework, this crowdsourcing of human capital can be used for accelerating scientific discovery in general, see Hill et al. (2016).

been used to advance medical research such as helping find cures for neglected diseases (where the critical missing link is computational work), see Davis et al.(2019).

15 Two other challenges include: 1) setting clear criteria (Brendt and Hurvitz 2005; Brunt et al. 2012; Kremer and Williams 2010; Murray et al. 2012) and 2) establishing a credible judge (Brendt and Hurvitz 2005; Brunt et al. 2012; Murray et al. 2012). The first challenge limits prizes to problems where the definition of success can be specified a priori. The second challenge is tied to reducing political risk so that serious investors will have recourse if they meet the prize criteria. Institutions such as the US Food and Drug Administration and the US Patent Office, buttressed by the US Court system, are in many ways de facto arbitrators of intellectual prizes. The need for such institutions is illustrated by John Harrison's struggle. As the eventual "winner" of the Longitude Reward (Sobel 1996), a prize offered by the British government in the eighteenth century, he only received his prize for developing a clock that allowed ships to accurately determine their longitude after petitioning King George III.

${ }^{16}$ In discussing approaches for estimating the appropriate size of a vaccine market commitment, Brendt et al. (2007) hint at using a Pareto optimal solution where the prize is set such that "At least to a first approximation, new firms will enter (and existing firms will invest more) until the NPV of investment for
} 
viable individual and entity within society and accurate estimates of development costs for every economically interesting problem. ${ }^{17}$ Without these, we are left with very little practical guidance from theory. Clearly if the prize is too low, then it will not generate sufficient capital as the expected profit falls below the acceptable threshold (determined by the flat expected profit threshold and, for very risky projects, the innovation boundary, see Fig. 1); if the prize is too high, then capital, which could have been used on other problems, will be wasted in duplicated efforts (Clancy and Moschini 2013; Murray et al. 2012).

Our proposed solution is to introduce a prize mechanism which is funded through different types of crowdsourcing ${ }^{18}$ and which is unbounded ${ }^{19}$ (allowed to grow over time). This mechanism solves important problems. First, it provides a legally binding structure (a nonprofit corporation with a contractual obligation-to the donorsto pay the prize to any entity satisfying the prize conditions) which is capable of aggregating large amounts of capital outside the control of governments ${ }^{20}$ (reducing political and procyclical funding risks that plague many policy initiatives). Second, it offers an alternative way for society to resolve the reward risk, by allowing interested funding parties two avenues to contribute capital toward the solution (see Fig. 2). Third, it solves the problem of how large to make the prize by, in effect, running a series of experiments over time as the prize increases-establishing (approximately) the minimum necessary reward needed to organize sufficient capital to successfully resolve the effort risk. The size of the prize thus emerges endogenously over time, rather than being determined, arbitrarily, a priori.

\section{Footnote 16 (continued)}

the marginal firm drops to zero." Because measuring these types of marginal utilities in practice is essentially impossible, they turn to an empirical approach, where the size of the prize is based on the average market size of existing (related) pharmaceutical products, with appropriate adjustments (e.g. there will be no associated marketing costs).

17 Put differently, if the uncertainty about the effort risk and reward risk is zero (meaning we know the amount of effort it will take to solve every problem and we also how much society will value each solution), it is then, in theory possible to mathematically determine an optimal size of a prize for each problem.

18 The rise of the Internet with its dramatic reduction in cost for communication and organization has increased opportunities for individuals to form alternatives to established institutions (Benkler 2006), such as governments and regulated capital markets. As an illustration, the ability to crowdsource funding for documentary films in the UK has broken the UK government's (via the BBC) near monopoly on determining the capital allocated to address "problems" (documentaries) and allowed capital to become available to address alternative "problems" supported by broad parts of the public not effectively represented through a democratic government (Sorensen 2012).

19 In practice, the fund would not be allowed to grow forever, but rather a governance mechanism (such as oversight by an established foundation) would be put in place which allows the purpose of the fund to be reviewed and modified, within limits, if at predetermined future dates those trusted with this task determine that the original purpose was unattainable (e.g. fundamental breakthroughs in science demonstrate that a cure for Type I diabetes is not possible) or no longer needed (e.g. a vaccine might be developed which stops people from developing Type I diabetes). The timing between these reviews should be substantial in length to provide a credible incentive for large scale investments to mature.

${ }^{20}$ From the perspective of solving a particular market failure (organizing capital to produce a specific public good), our proposed Ever-Growing Prize Fund could be viewed as a global, "single-purpose government". 


\section{Push mechanisms and the patent repository}

The economist Frank Knight made an important distinction between risk and uncertainty $^{21}$ (Knight 1921). Solutions to many problems are complicated but well known (e.g. running a restaurant), hence the associated risks (effort and reward) are quantifiable. Alternatively, when solutions fall outside the domain of human knowledge (e.g. curing diabetes) then the associated risks are more than exorbitant, they are unknowable. When the probability of going bankrupt, regardless of how much capital you have, is unknown, it is impossible to calculate an expected profit, and the standard economic framework of maximizing expected utility fails. A rational, disciplined investor will be unwilling to bear the effort risk for problems with Knightian uncertainty. ${ }^{22}$ Problems beyond the innovation boundary in Fig. 1 thus remain unaddressed.

Push mechanisms allow governments (and philanthropies) to bear the effort risk by providing subsidies (e.g. grants and tax credits). The challenges with subsidies are oversight and taste and can be viewed as finance problems. Good financial managers align the amount of capital invested in market segments based on their judgement of profitability. For governments, the alignment of tax revenue (capital) to a portfolio of problems should be based on the preferences of their citizens. Depending on the concentration of power within a government, the ability for citizens to affect this alignment of capital varies and is at best limited. ${ }^{23.24}$

The ever-present reality of a subsidy-driven research enterprise is that to continue to exist inventors must ensure future subsidies. Only after that condition is satisfied can they focus on research priorities. The problems of taste (who should be given a grant) and oversight (ensuring that the researcher spends the capital as

\footnotetext{
${ }^{21}$ In some sense, the distinction put forward by Knight, see Knight (1921), (and echoed by Keynes in his "animal spirits," see Keynes 1936, characterization of investing) can be viewed in terms of the confidence one has in their ability to predict. For our purposes, agents can make decisions under risk when a reasonable amount of related data exists to form credible predictive models (and hence calculate a risk adjusted expected profit), while agents make decisions under uncertainty (also called ambiguity, see Ellsberg 1961) when they have no real credible predictive model (e.g. the ordering of gambles results in violations of the Savage axioms, again see Ellsberg 1961) and they are essentially "walking in the dark". In the face of innovation, where the likelihoods of outcome are to be estimated with very little evidence or prior expertise, choices will be biased away from options with ambiguity and toward options with "known risks", (Ellsberg 1961).

22 Many entrepreneurs who tackled technology problems with Knightian uncertainty did so from their dorm room or parent's garage exhibiting preferences for ambiguity over risk (an option noted as preferred for a minority of the population, Ellsberg 1961), which we speculate came in part because of their family support and a pioneering advantage as the incalculable uncertainty in their industry turned into quantifiable risk.

23 The problem of aggregating demand for public goods through a voting system is in Paul Samuelson's words "a swampland of mathematical politics, ending up with inconclusive behavior patterns by legislatures, factions and parties, running inventibly afoul of Arrow's Impossibility Theorem." (Samuelson 1969; see also Arrow 1963).

${ }^{24}$ In the case of philanthropies, alignment of capital is driven by the idiosyncratic preferences of the philanthropist. As a result, many important problems (especially those with Knightian uncertainty) are not addressed. The solution is to create a new mechanism allowing the public to "vote with their pocketbook," (Grabowski 2008).
} 
promised) are exasperated by the information asymmetry between the grant-agency and the researcher ${ }^{25}$ (the researcher has better knowledge about their true ability) and, typically, the lack of objective measurements to determine the societal value of research. ${ }^{26}$

Competitive markets (and prizes) address the challenges of taste and oversight but within limits. With few exceptions (philanthropy being one), the primary mechanism for bringing Knightian problems within the innovation boundary has been government funding, ${ }^{27}$ but that leaves the choice of the problems to be addressed at the mercy of the collective judgement of the political process. ${ }^{28}$ Likewise, philanthropic funding remains at the mercy of the idiosyncratic preferences of philanthropists. ${ }^{29}$ As a society, we can do better.

To help increase the concentration of and access to ideas that can lead to a solution of a target problem, we propose creating a legal entity that we call the Patent Repository, which is affiliated with the cure fund (see Fig. 3). Firms and research organizations with patents can grant the Repository an exclusive, limited-use (limited to solving the target problem-e.g. curing diabetes) license. All remaining rights are retained by the firm or research organization. The Repository then grants an open-source, limited-use, research license for all the patents it controls to the general public (i.e. to any and all legal entities globally).

A legal entity claims the prize by submitting a cure patent and then having the cure patent verified by a designated outside entity. ${ }^{30}$ If the cure patent uses any of

\footnotetext{
${ }^{25}$ The incentive to "keep the lights on" can lead researchers to overpromise and mislead, as caricatured in the popular press (Miller 2014). One particularly egregious example of the challenge of effective oversight is the failed effort in the 1980s of the U.S. Agency of International Development to develop a malaria vaccine (Desowitz 1991), wasting $\$ 60$ million.

${ }^{26}$ The fact that fundamental research (which extends knowledge so effort risk can become quantifiable) has no ready market, means that profit cannot be used (as in competitive markets) to measure the societal good brought about by a subsidy.

${ }^{27}$ Developing a self-driving car was incalculably hard, until the US Defense Advanced Research Projects Agency (DARPA) sponsored a series of prizes ${ }^{32}$ where self-driving cars progressed from driving alone across a desert to driving in a mock town with traffic; reducing the associate Knightian uncertainty to risks worth taking by firms.

${ }^{28}$ We readily concede that when faced with an existential threat, such as the space race between the United States and the Soviet Union, governments of all types can adroitly align excess capital with the public will; this can be viewed as special case in governance where the problems highlighted in Footnote 23 are overcome.

${ }^{29}$ Because of donation shortfalls, the March of Dimes Foundation revoked awards to 37 researchers (Maxmen 2018). In a related story, Bill Gates announced that the Bill and Melinda Gates Foundation "will give its 'total attention' to the COVID-19 pandemic — even at the risk that its other public health work will suffer," (Cookson 2020).

${ }^{30}$ In the case of curing diabetes, the validation could be done by completing an FDA approved Phase III clinical trial, based on the Intellectual Property in the Cure Patent, which successfully meets the criteria for the prize.
} 


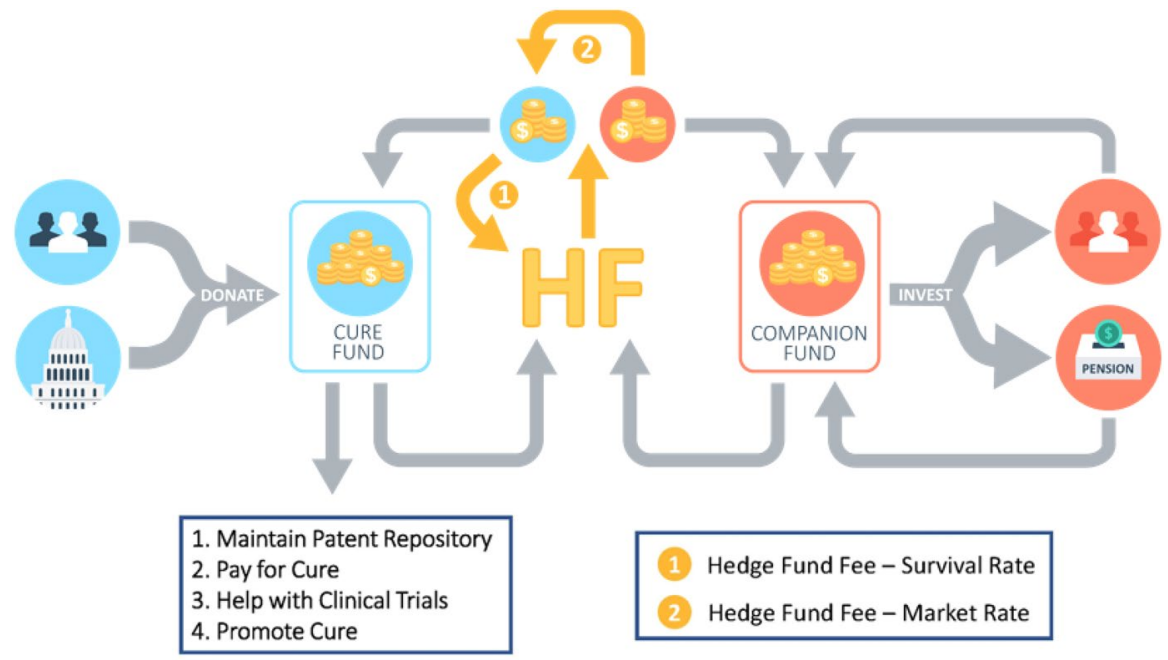

Fig. 2 HF Hedge Fund, which can invest in a range of assets of varying degrees of risk, like an established trust fund. Capital managed by the hedge fund comes from two sources: a Cure Fund (funded by crowdsourced donations) and a Companion Fund (which manages money for those sympathetic with finding a solution to the target problem, but who are not ready to donate directly to the Cure Fund). Profits from investments funded by the Cure Fund return to the Cure Fund, minus a (1) below-market management fee; profits from the Companion Fund return to the Companion Fund, minus a (2) standard market management fee, which is subsequently donated to the Cure Fund

the patents in the Repository (derivative patents ${ }^{31}$ ), then the firms or research organizations holding these derivative patents will receive a portion of the prize. ${ }^{32}$ In exchange, the Repository is allowed and required to grant a royalty-free, limited-use license for the cure patent and derivative patents to the general public.

This legal structure reduces effort risk and provides a mechanism for society to more fully resolve the free-rider risk. First to the effort risk: patents turn public goods (knowledge) into private goods, which restricts their use. ${ }^{33}$ Our proposed

\footnotetext{
${ }^{31}$ The limited use, general public licenses issued by the Repository will contain a grant-back clause, providing a clear legal mechanism for derivative patents to both be used in a cure patent and to ensure payment.

32 There are a variety of potential schemes for dividing the prize money between the holder of the cure patent and the derivative patents; our preference would be to give the bulk of the reward (e.g. 2/3) to the one who "put it all together" and then divide the rest equally among those who "laid the foundation" for the solution. This approach could be augmented by the creation of a secondary market for shares in special purpose firms which only own the rights to a potential derivative patent, in the spirit of Meloso et al. (2009).

${ }^{33}$ Innovation is typically cumulative, with subsequent breakthroughs arriving because scientists are able to "stand on the shoulders of giants," see Williams (2018), as Isaac Newton famously stated. What happens if scientists are restricted from using ideas in their research, see Heller and Eisenberg (1998) told that they must wait or pay in order to stand on the shoulders of some giants because of intellectual property rights? Empirical evidence from innovation related to the Human Genome (Williams 2013) and access to genetically engineered mice (Murray et al. 2016), suggests that removing the non-excludable nature of a public good (see Footnote 5) hurts cumulative innovation. These results are tempered somewhat by the finding that for patented genes "any effects of patents on follow-on innovation appear to be
} 
structure undoes this, for a narrowly defined purpose, by allowing patents within the boundaries of the Repository to become public goods once again, meaning in part that the effort needed to negotiate licenses for investigating solutions to the target problem are eliminated. In addition, the Repository acts as a collection point for ideas related to the target problem. Together these diverse ideas can become meaningful, as inventions are often based on novel combinations of preexisting knowledge. ${ }^{34}$

With regards to the free-rider risk: the value that society will pay for a solution to a problem and the reward that the innovators who solve the problem receive, should be linked. In addition, all the essential innovators should receive part of the prize, even if their patent has expired. In contrast to US and European patents, which expire 20 years after filing, patents within the Repository de facto have no expiration dates in the sense that the Repository will reward derivative patents regardless of whether the patents are still in force externally. This pushes researchers, willing to "bend their research" toward discovering a foundational part of a solution to a target problem, because a mechanism is in place to guarantee their efforts are rewarded.

\section{Combining an ever-growing prize with a patent repository}

Our proposed solution, combining an Ever-Growing Prize with a Patent Repository, provides an alternative mechanism that better aligns the public interest with the allocation of capital towards important problems. The ever-growing prize component sets an emergent price (via the increasing prize value ${ }^{35}$ ) for target problems, which will attract the minimum amount of capital needed to resolve both the associated effort risk and reward risk.

The Patent Repository component provides a legal structure which reduces cost of exploration, provides a reward for solutions which is not dependent on monopoly pricing, and offers an alternative mechanism to resolve the free-rider risk. While each component in isolation addresses only part of the problem (leaving inventors exposed to important, unaddressed forms of risk), in combination all three forms of risk inherent to the innovator's dilemma are addressed-an important condition to incentivize inventors to tackle problems of Knightian uncertainty, such as finding a cure for diabetes.

\footnotetext{
Footnote 33 (continued)

qualitatively small," (Sampat and Williams 2019). A related problem arises when "giants" block ideas from entering the public domain (e.g. being published), because the ideas conflict with or undermine the "giants"” ideas (Azoulay and Graff-Zivin 2018). The existence of a prize structure and repository, such as we propose, allows and rewards the combination of existing ideas, regardless of their perceived merit, and provides incentives in line with the ideal approach to science.

${ }^{34}$ In 1839, the French Government purchased patent rights to a vastly improved method of photography from Louise Daguerre and then placed the patent in the public domain (Murray et al. 2012; Sobel 1996; Williams 2012). This spurred a period of dramatic innovation in photography. This ability to readily experiment gives (geographic) clusters of firms a distinct "knowledge spillover" advantage in innovation (Fleming 2001; Nelson and Winter 1982), an advantage that we anticipate the Repository would facilitate among those working to solve the target problem.

35 See Footnote 8.
} 


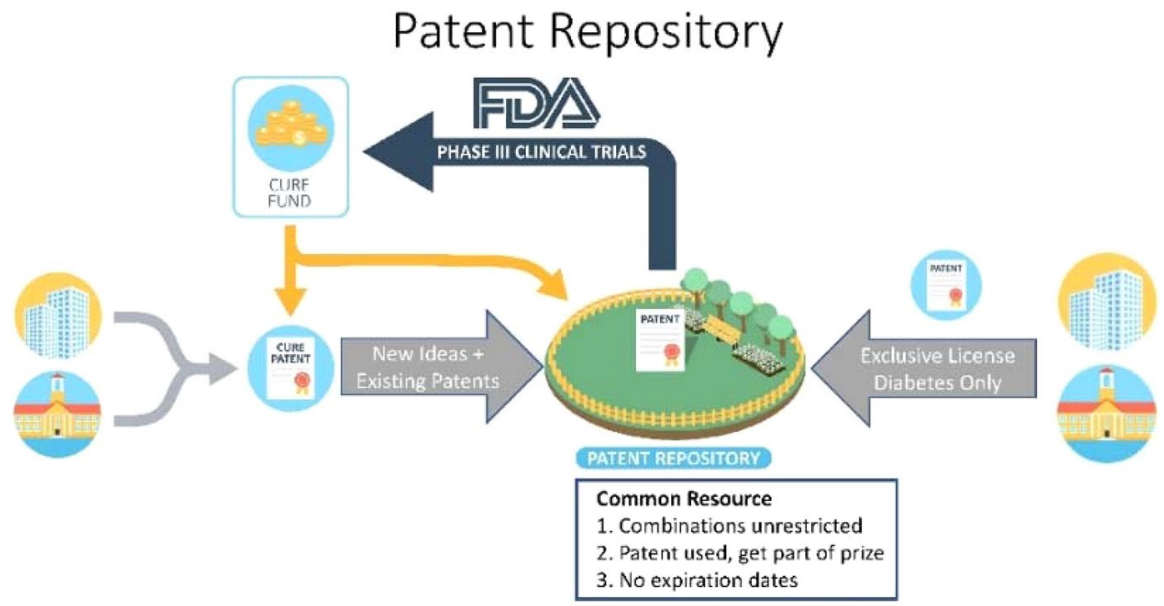

Fig. 3 The Patent Repository holds exclusive, limited-use (limited to solving the target problem-e.g. curing diabetes) licenses for patents. If a subsequent cure patent is validated (via clinical trials by the FDA which would be the responsibility of those seeking to claim the prize, but could - in special casesbe aided by the cure fund), the prize is distributed to the cure patent (and derivative patents) holders, even if the initial patent protection for the derivative patents has expired. In exchange, all intellectual property needed to solve the target problem is put into the public domain

An important additional advantage of the proposed solution is that it can result in the "MacGyver Effect" 36 where novel but (by market standards) uneconomic solutions to problems become viable, see Vanderbilt (2019). These are the problems that fall below the expected profit threshold in Fig. 1, which we illustrate in the next section.

\section{The MacGyver effect and cystic fibrosis}

Imagine an Ever-growing Prize and associated Patent Repository with a prize that rewards a treatment, which improves the average lung capacity of Cystic Fibrosis (CF) patients by a fixed amount. Historically, two competing therapeutic approaches could have been viable contenders for this prize, but to date, only one treatment is available.

Upon the discovery of a gene mutation, the CF Foundation took the unusual and laudable risk of investing over $\$ 150$ million (Pollack 2014), to develop an FDA

\footnotetext{
36 MacGyver is a US espionage show where the main character creates innovative items (e.g. lie detector, rocket, telescope, spectroscope) using materials readily at hand to solve problems key to resolving the plot. Such ingenious and inexpensive solutions are often found where we least expect leading many to question the credibility of the source of a potential solution, but the existence of a prize mechanism would allow society to overlook prejudices and reward valid solutions.
} 
approved treatment. ${ }^{37}$ Starting at around the same time, Political Science Professor Valerie Hudson, mother of three boys with CF, took a MacGyver approach. Her review of the literature led to a conjecture that low levels of Glutathione (GSH) in $\mathrm{CF}$ patient lungs (and airways) could be redressed with a regular oral (nebulized) dose of GSH, which would in turn reduce mucus and improve lung functionality (Hudson 2001; Richards 2002). The oral GSH approach is not patentable and has a marginal cost on the order of $\$ 1200$ a year; ${ }^{38}$ to date, Professor Hudson and a small group of volunteers have demonstrated limited but promising clinical success (Visca et al. 2008, 2015). The CF Foundation approach was patented, sold to Vertex Pharmaceuticals for $\$ 3.4$ billion $^{39}$ and is available for around $\$ 300,000$ a year (Pollack 2014).

The fact that the oral GSH approach (a potentially viable treatment) has no path to secure monopoly pricing nor offer academic prestige, has left it bereft of capital; this represents not only a market failure, but in our view, a philanthropic failure.

The existence of an Ever-Growing prize (e.g. starting at around $\$ 150$ million) could provide an economic reward that, we conjecture, would be able to attract venture capital sufficient to pay for the FDA clinical trials ${ }^{40}$ for a variety of different approaches including the oral GSH approach. ${ }^{41}$ With the amount of capital available to the $\mathrm{CF}$ research community, implementing a mechanism which circumvents unrestrained profit motives, could likely bring this second MacGyver-type treatment to market, which would improve the fate of CF patients as they would be better served by having two treatments instead of one.

\section{Curing diabetes}

Even though effective treatments for Type I diabetes (measuring blood sugar and injecting needed insulin) exist, there is broad public interest in developing a cure ${ }^{42}$ (having the body produce insulin once again and properly regulate it). Currently, the

\footnotetext{
${ }^{37}$ Among the many gene mutations leading to a defective CFTR protein, causing restricted flow of salt, water through cell membranes in Cystic Fibrosis patients, around 5\% have the G551D mutation. Ivacaftor, known commercially as Kalydeco®, improves cell membrane diffusion which helps increase lung capacity on the order of $10 \%$ (using forces expiratory volume in $1 \mathrm{~s}, \mathrm{FEV}_{1}$ as a measure) in such patients, helping extend life expediency of CF patients by up to 9 years, see Whiting et al. (2014).

${ }^{38}$ Based on private communication with Professor Hudson.

${ }^{39}$ In 2014, the (discounted) average cost of a lifetime treatment (for patients under 12 with no or little lung damage) using Ivacaftor was estimated to be between $£ 51$ and $£ 113$ million (Whiting et al. 2014). The exchange rate between U.S. $\$$ and $£$ in 2014 was approximately $1.5 \$ / £$, making this estimated range between $\$ 77$ and $\$ 170$ million.

${ }^{40}$ Private communications with Professor Hudson indicated that she collaborated with researchers in Italy to conduct some of the trials because she could not secure the $\$ 5.4$ million needed to satisfy the FDA's pre-clinical trial requirements.

${ }^{41}$ In this example, the cure patent would not be based on derivative patents, highlighting the ability for the proposed mechanism to organize capital where philanthropies have failed for largely economic reasons.

${ }^{42}$ The American Diabetes Association raises on the order of $\$ 120$ million a year which is split essentially equally across research, education and fundraising, while the National Institute of Health spends over \$700 million a year on diabetes related research (KPMG 2017; National Institute of Health 2019).
} 
capital devoted to developing a cure is limited to push subsidies. This is due primarily to the effort risk being unknowable, as a cure would require advances in basic science. ${ }^{43}$ Even if the effort risk was quantifiable, development of a cure would face the classic product cannibalization challenge, as the primary candidates for developing a cure (e.g. pharmaceutical companies) would require an expected profit premium due to the lost profits from the elimination of their existing diabetes treatments.

How would our proposed mechanism change the flow of capital directed at developing a cure? Undoubtably some push capital would be diverted to fund the prize, ${ }^{44}$ but we anticipate that a spotlight effect would increase the overall concentration of capital. Initially, push-based researchers may be incentivized to place patentable research results in the Repository. As the prize and the accumulated Intellectual Property (IP) grow, small start-up teams funded by venture capitalists ${ }^{45}$ (unhindered by the prospect of the loss of treatment profits) may emerge to test the viability of the IP in the Repository. Then, as ambiguity decreases (and is no longer "Knightian"), curing diabetes may move inside the innovation boundary, attracting even more capital ${ }^{46}$ and enticing pharmaceutical companies to invest in promising startups or seek a cure via their internal R\&D. ${ }^{47}$

A cure would consist of having a person with Type I diabetes: (1) produce insulin; (2) regulate that insulin; (3) require no further interventions; and 4) have same health risks as a similar person who never had Type I diabetes. To be effective, the formal cure definition would have to be written in a manner such that a credible claim could be enforced in court. Given the incremental manner in which science advances, a number of prize variations might be imagined, e.g. offering a large portion of the prize if a small percent of patients were cured, then distributing the remainder of the prize in a prorated fashion as larger percentages are cured.

In addition to paying for a cure, a portion of the cure fund would be used (as noted in Fig. 2) to maintain the Patent Repository, help non-traditional groups

\footnotetext{
43 The amount of effort needed to advance basic science is a classic example of ambiguity or Knightian uncertainty.

44 We conjecture that new donor capital would flow into the prize fund as it offers a different incentive structure, which would attract those suspicious of the efficacy of existing push mechanisms.

45 The investment landscape for funding early-stage research development through product development has expanded considerably in the recent past going beyond simply venture capital funding (Booth 2009; Fernandez et al. 2012; Fernandez et al. 2013; Ford and Nelson 2014), including novel proposed securitization (Fernandez et al. 2013), funding mechanisms to bridge the "valley of death" that occurs between the discovery of viable treatments and subsequent clinical trials.

46 A lottery like concentration of effort would likely manifest, as with the Ansari XPRIZE, where a \$10 million prize attracted over $\$ 100$ million (Murray et al. 2012), in capital to try and win the prize.

47 Once a viable cure is possible, making the arrival of a cannibalizing product likely, incentives change from trying to preserve treatment profits to becoming the entity that gets the prize for developing a replacement (Chandy and Tellis 1998; Tellis 2013).
} 
navigate FDA clinical trials, ${ }^{48}$ and establish endowments at major medical centers with the mandate to widely promote the cure.

\section{What could go wrong?}

Utopian ideals are often based on somehow having altruism dominate human interaction-typically through a critical mass of enlightened individuals; subsequent proposed structures then crumble when they encounter the realities of self-interest. The question we explore is not whether altruism can rise to dominate, but rather, whether altruism can use legal structures to entice additional altruism as well as avert negative consequences of behavior driven purely by self-interest. We address two critical questions that may arise from the perspective of self-interest: (1) how would one get such a prize mechanism started, particularly with respect to the aggregation of IP; and (2) would not existing profit maximizing entities (e.g. pharmaceutical companies, which are making substantial profits treating diabetes) seek to circumvent or thwart the mechanism?

There is an element of altruism required for our approach to work, but the altruism is restricted to a select few - the hedge fund owners. They provide the seed money for the prize and pay for developing legally binding contracts which stop the prize from being diverted by political expediency or sudden changes in philanthropic preferences. They also facilitate altruism in a broader sense, by managing investments for those who care about the target problem but are not yet ready to be altruistic with their capital, and then donate a portion of their management fee to the prize. The existence ${ }^{49}$ of a viable legal structure and a growing prize will help entice innovators to contribute IP to the Repository, but in cases where the target problem is suitably hard (e.g. years, if not decades, away from a solution) it may be necessary, and readily implementable in the mechanism described above, to set a series of intermediate prizes (e.g. getting a person with Type I Diabetes to produce insulin again-regardless of whether it can be effectively regulated) to entice participation.

Not everyone will want to participate in the mechanism; firms that have a profitable treatment for diabetes, for example, have a perverse economic incentive to purchase promising cure IP for diabetes with the explicit purpose to halt development (a practice called "shelving"). The existence of the Repository, however, offers an alternative route for commercialization and, at a minimum, should make shelving promising technologies more expensive. ${ }^{50}$ In addition, once the proposed mechanism brings us closer to a cure, profit maximizing firms may seek to circumvent

\footnotetext{
48 A successful completion of Phase III clinical trials would be required to claim the prize.

49 It would be advisable to start with a simpler problem, such as developing an effective treatment for Cystic Fibrosis, as a way of developing and testing an ideal set of legal contracts, running and maintaining the Patent Repository and judging the success of potential claimants.

50 Not all individuals (or organizations) will be driven purely by the motive of maximizing profit (prestige, seeing one's work make a difference, and altruism are additional motivators); for those driven purely by profit, the potential share of the prize money offered by the hedge fund can act as a lower bound for the value of any potential cure IP.
} 
the mechanism and develop a cure outside of the Repository. If a blocking patent exists $^{51}$ in the Repository, then firms would be required to participate in the mechanism. If a blocking patent does not exist, the value of the prize-compared to the net present value of the cure, at a price that the "market can bear"-may not be enough and the firm might forgo the prize and patent the cure. In that case, not only has the proposed mechanism been instrumental in bringing a cure to market, it also provides competitors a clear economic reward for developing alternative (e.g. MacGyverlike) solutions.

\section{Conclusion}

Although prizes are regularly used and large trusts aggregate capital intent on solving specific societal problems, our proposal offers a novel mechanism for organizing capital to produce public goods. One key difference to previous approaches, has to do with scale; another is the type of innovation risk our mechanism will bear; and yet another has to do with how existing patents are treated. Our prize is unbounded by time: it grows until someone satisfies the criteria. ${ }^{52}$ It is also unbounded by size, providing a mechanism where the minimum amount of capital that society needs to solve a problem can be secured. Furthermore, our mechanism addresses the freerider risk and resolves the reward risk. Within the Patent Repository, patented ideas regain the essential feature of non-exclusion, for the target problem, facilitating an unhindered approach to cumulative innovation with a clear path for rewarding incremental contributions to a working solution. We anticipate that our approach will succeed where others have failed: such as (1) where the problem is below the expected profit threshold and potential rewards (e.g. patent, academic prestige) are not considered attractive enough to motivate an effort, or (2) where the effort risk is so ambiguous that the problem is outside the innovation boundary and the threat of bankruptcy is sufficient to deter efforts from market participants.

Finally, while the core problem addressed in this article is economic in nature, the proposed solution has direct relevance to the advance of science as this advance requires that scientists have access to capital ${ }^{53}$ commensurate to the problems society wants them to address (Gambardella 1995; Pavitt 1963; Stamp 1933; Stephan 2015). Not only will our mechanism resolve the question of how to determine the minimum reward needed as well as offer an alternative path for pooling public

\footnotetext{
51 It is possible to increase the cost of trying to circumvent the mechanism by changing patent law (exclusively for IP placed in the Repository) in ways that increase the chances that the Repository holds a blocking patent. Two ideas would be: (1) to extend the length of the patent protection (for the target problem only) if the patent is placed in the Repository - the length of the protection of rights of a patent, outside of the Repository, would remain unchanged; and (2) require all derivative patents of a patent in the Repository to also be placed in the Repository - all other rights of a derivative patent would be controlled by the holder of the derivative patent. Since patent law is a legal construct intended to help foster innovation and the creation of public goods, it is credible to imagine that such changes might be enacted by legislatures.

52 See Footnote 19.

53 "Although a public good, science is not a 'free' good," see Stephan (2015).
} 
goods, with the intent of solving a particular problem, under one legal structure (with a clear division of the reward), it also brings a new level of public determinism for redressing Marx's critique of capitalism. Members of the public determine which problems to solve, as the hedge fund approach can only be effective for problems which a sufficient portion of the public deems worthy of investment. ${ }^{54}$ The crowdsourcing element of our mechanism introduces a democratic element to the most challenging political part of a society's march of progress: aligning the will of the public with the use of the excess capital it produces.

Author contributions Both authors contributed to the conception and development of the manuscript, although the original idea was identified by Liechty. Both authors contributed to previous versions of the manuscript. Both authors read and approved the final manuscript.

Funding No applicable.

Availability of data and materials No applicable.

Code availability No applicable.

\section{Declarations}

Conflicts of interest/competing interests Not applicable.

\section{References}

Anomaly J (2015) Public goods and government action. Polit Philos Econ 14(2):109-128

Arrow K (1963) Social choice and individual values. Wiley, New York

Azoulay P, Graff-Zivin F (2018) One superstar funeral at a time. Science 361(6408):1195

Bateman B (2015) Analyzing Market Failure: Adam Smith and John Maynard Keynes. Hist Polit Econ 47(1):127-144

Bator F (1958) The anatomy of market failure. Q J Econ 72(3):351-379

Benkler Y (2006) The wealth of networks: how social production transforms markets and freedom. Yale University Press

Berndt R, Hurvitz J (2005) vaccine advance-purchase agreements for low-income countries: practical issues. Health Aff 24(3):653-665

Berndt ER, Glennerster R, Kremer MR, Lee J (2007) Advance market commitments for vaccines against neglected diseases: estimating costs and effectiveness. Health Econ 16:491-511

Bock J (1964) Fiddler on the roof: (from the Broadway Musical "Fiddler on the roof") RCA Victor

Boldrin M, Levine D (2013) The case against patents. J oEcon Perspect 27(1):3-22

Booth BL (2009) Beyond the biotech IPO: a brave new world. Nat Biotechnol 27:705-709

Brunt L, Lerner J, Nicholas T (2012) Inducement prizes and innovation. J Ind Econ 60(4):657-696

Cernuschi T, Furrer E, Schwalbe N, Jones A, Berndt E, McAdams S (2011) Advance market commitment for pneumococcal vaccines: putting theory into practice. Bul World Health Org 89(12):913-918

Chandy RK, Tellis GJ (1998) Organizing for radical product innovation: the overlooked role of willingness to cannibalize. J oMark Res 35(4):474-487

Christensen C (1997) The innovator's dilemma: when new technology causes great firms to fail. Harvard Business Review Press

\footnotetext{
54 With their donations, with how their pensions are managed and by influencing existing push mechanisms to contribute to the Cure Fund.
} 
Clancy M, Moschini G (2013) Incentives for Innovation: patents prizes and research contract. Appl Econ Perspect Policy 35(2):206-241

Cookson C (2020) Gates foundation to concentrate on coronavirus. Financial Times, Berlin

Davis S, Button-Simons K, Bensellak T et al (2019) Leveraging crowdsourcing to accelerate global health solutions. Nat Biotechnol 37:848-850

Desowitz R (1991) The Malaria capers: tales of parasites and people. W.W. Norton, New York

Ellsberg D (1961) Risk, ambiguity, and the savage axioms. Q J Econ 75(4):643-669

Fernandez JM, Stein RM, Lo AW (2012) Commercializing biomedical research through securitization techniques. Nat Biotechnol 30:964-975

Fernandez JM, Lo AW, Stein RM (2013) Can financial engineering cure cancer? Am Econ Rev 103:406-411

Fleming L (2001) Recombinant uncertainty in technological search. Manag Sci 47:117-132

Ford D, Nelson B (2014) The view beyond venture capital. Nat Biotechnol 32:15-23

Gambardella A (1995) Science and innovation: the US pharmaceutical industry during the 1980s. Cambridge University Press, Cambridge

GAVI The Vaccine Alliance (2017) Advance market commitment for pneumococcal vaccines, Annual Report 1 Jan-31 December 2017

Gewin V (2017) Grand challenges. Nature 551:129-131

Glennerster R, Kremer M, Williams H (2006) Creating markets for vaccines. Innov Winter 1(1):67-79

Grabowski H (2008) Follow-on Biologics: data exclusivity and the balance between innovation and competition. Nat Rev Drug Discov 7:479-488

Hardin G (1968) The Tragedy of the Commons. Science 162(3859):1243-1248

Heller M, Eisenberg R (1998) Can patents deter innovation? The anticommons in biomedical research. Science 280(5364):698-701

Hill S, Heiser L, Cokelaer T et al (2016) (2016), Inferring causal molecular networks: empirical assessment through a community-based effort. Nat Methods 13:310-318

Hudson V (2001) Rethinking cystic fibrosis pathology: the critical role of abnormal reduced glutathione (GSH) transport caused by CFTR mutation. Free Radic Biol \& Med 30(12):1440-1461

Kalil T (2006) Prizes for Technological Innovation, Discussion Paper 2006-08. The Hamilton Project, Brookings Institution, Washington DC

KEI Research Note (2008) Selected innovation prizes and Reward Programs, Washington, DC

Keynes J (1936) The general theory of employment, interest and money. Macmillan, London

Knight F (1921) Risk, uncertainty and profits. Schaffner \& Marx; Houghton Mifflin Company, Boston

KPMG (2017) American Diabetes Association, Consolidated Financial Statements and Consolidated Schedules. http://main.diabetes.org/dorg/PDFs/Financial/ADA2017ConsolidatedFinancials.pdf. Accessed 31 Dec 2017

Kremer M, Williams H (2010) Incentivizing innovation: adding to the toolkit. In: Lerner J, Stern S (eds) Innovation policy and the economy, vol 10. University of Chicago Press, Chicago

Levine D (2009) Eyes on the Prize? Sci 323(5919):1296-1297

Marx K, Engels F (1848) The Communist Manifesto. London, Chicago, Ill. :Pluto Press, 1996

Maxmen A. (2018), Scientists Stunned to as Medical Non-Profit Group Abruptly Ends Research Grants, Nature News, August 2

McKinsey \& Company (2019) And the winner is ... Capturing the promise of philanthropic prizes. Research Report

Medema S (2007) The hesitant hand: Mill Sidgwick, and the evolution of the theory of market failures. Hist Polit Econ 39(3):331-358

Meloso D, Copic J, Bossaerts P (2009) Promoting intellectual discover: patents versus markets. Science 323(5919):1335-1339

Miller W (2014) Woo-Hoo, i found a cure. https://www.gocomics.com/nonsequitur/2014/06/24. Accessed 24 June 2014

Mueller-Langer F (2013) Neglected infectious diseases: are push and pull incentive mechanisms suitable for promoting drug development research? Health Econ Policy Law 8(2):185-208

Murray F, Stern S, Campbell G, MacCormack A (2012) Grand innovation prizes: a theoretical, normative and empirical evaluation. Res Policy 41:1779-1792

Murray F, Aghion P, Dewartripont M, Kolev J, Stern S (2016) Of mice and academics: examining the effect of openness on innovation. Am Econ J Econ Policy 8(1):212-252

National Institute of Health (2019) Estimates of funding for various research condition, and disease categories (RCDC). https://report.nih.gov/categorical_spending.aspx. Accessed 19 Apr 2019 
Nelson R, Winter SG (1982) An evolutionary theory of economic change. Belkap, Cambridge

Pavitt K (1963) Research, innovation and economic growth. Nature 200(4903):206-210

Pollack A (2014) Deal by cystic fibrosis foundation raises cash and some concerns. New York Times

Reich M (2000) The Global Drug Gap. Sci 287(5460):1979-1981

Richards L (2002) A mother's fight against CF. Modern Drug Discov 5(4):19-20

Sampat B, Williams H (2019) How do patents affect follow-on Innovation? Evidence from the Human Genome. Am Econ Rev 109(1):203-236

Samuelson P (1969) Pure theory of public expenditure and taxation. In: Margolis J, Guitton H (eds) Public economics: an analysis of public production and consumption and their relations to the private sectors. Macmillan, London

Samuelson P (1970) Economics: an introductory analysis, 8th edn. McGraw-Hill

Schwartz J (2004) Private rocket ship visits space again to win $\$ 10$ million prize. New York Times

Sobel D (1996) Longitude: The true story of a lone genius who solved the greatest scientific problem of his time. Penguin Press, New Your

Sorensen I (2012) Crowdsourcing and outsourcing: the impact of online funding and distribution on the documentary film industry in the UK. Media Cult Soc 34(6):726-743

Stamp J (1933) Must science ruin economic progress. Nature 132(3333):429-432

Stephan P (2015) How economics shapes science. Harvard University Press

Tellis GJ (2013) Unrelenting innovation: how to create a culture for market dominance. John Wiley \& Sons

Vanderbilt T (2019) "Reverse Innovation" could save lives. Why aren't we embracing it? The New Yorker

Visca A, Bishop C, Hilton S, Hudson V (2008) Improvement in clinical markers in CF patients using a reduced glutathione regimen: an uncontrolled, observational study. J Cystic Fibros 7:433-436

Visca A, Bishop C, Hilton S, Hudson V (2015) Oral reduced l-glutathione improves growth in pediatric cystic fibrosis patients. J Pediatr Gastroenterol Nutr 60(6):802-810

Whiting P, Burgers L, Westwood M, Ryder S, Hoogendoom M, Armstrong N, Allen, A, Severens, H, Kleijnen J (2014) Ivacoftor for the treatment of patients with cystic fibrosis and the G551D mutation: a systematic review and cost-effectiveness analysis, Health Technol Assess, no 18.18, Southampton (UK): NIHR Journals Library

Williams H (2012) Innovation inducement prizes: connecting research to policy. J Policy Anal Manag 31(3):752-776

Williams H (2013) Intellectual property rights and innovation: evidence from the human genome. J oPolit Econ 121(1):1-27

Williams H (2018) On the shoulders of giants. Science 361(6408):1195 